Results alarmed the DOTC and legislators crafting bills for children safety. SKP was invited to be a member of the Technical Working Group of the Committee on Transportation of Congress.

Significance/Contribution to the Field Recognition of injuries caused by motorcycle users is leading to more stringent policies and programmes involving motorcycles.

\section{SAFE KIDS PHILIPPPINES' DATA ON MOTORCYCLE CULPABILITY IN ROAD TRAFFIC INJURIES USED AS REFERENCE FOR CONGRESS BILLS}

doi:10.1136/injuryprev-2012-040590s.2

${ }^{1} \mathrm{M}$ Alcantara, ${ }^{1} \mathrm{~A}$ Rolloque, ${ }^{1,2} \mathrm{R}$ Consunji, ${ }^{1} \mathrm{MT}$ Perez, ${ }^{1} \mathrm{PD}$ Azas. ${ }^{1}$ Safe Kids

Philippines; ${ }^{2}$ Philippine General Hospital, UP College of Manila, Philippines

Background Motorcycles have begun to make an impact on the roads of the Philippines as a major form of transportation because of cheap availability. Safe Kids Philippines data have shown that motorcycles are culprits in crashes that involve children 14\% of more than 3300 crashes that involve children pedestrians. Safe Kids Philippines aims to reduce the number of children being injured because of motorcycles.

Aims/Objectives/Purpose To bring the data to the attention of policy makers to legislate the involvement of children as motorcycle victims and motorcycle riders. Data will support the advocacy of Safe Kids Philippines (SKP) in reducing injuries on and around motorcycles.

Methods SKP administered pre and post tests to children in 49 schools in five beneficiary cities. More than 12000 children were asked if they have been involved in road crashes within their school zones. Data was collated and shared with the Technical Working Committee of the Department of Transportation and Communication (DOTC), and legislators in Congress among others. Results/Outcomes Of more than 12000 children given pre and post tests, $3384(26 \%)$ students experienced road traffic injuries. Culprits of the road traffic injuries were the bicycles with 1465 (43\%), motorcycles 464 (14\%), pedicabs $455(13 \%)$ and tricycles 371 (11\%). 